\title{
Energy Release Rate for Fiber Reinforced Polymer Composite
}

\author{
Hisham Mohammed ali Hasan ${ }^{1}$, Elaf Addel Albdere ${ }^{2}$ \\ University of Al-Qadisiyah
}

\begin{abstract}
An experimental investigation using drag-out tensile test to calculate the interfacial shear strength for different embedded lengths and radius of Kevlar -49, carbon and ultra high polyethylene fibers reinforced epoxy matrix, the energy release rate calculated by using Nairn model. The energy release rate increase as the embedded fiber length increase and also for fiber radius for perfect adhesion, for specimens with bubbles at interface which seems to reduce the fracture toughness the energy release rate be less than specimens with perfect adhesion, the thermal stress and friction forces were included in the energy release rate in Kevlar-49 and carbon reinforced epoxy the interfacial shear force due to friction part decrease while in solid ultra high polyethylene the interfacial shear force due to friction part increase.
\end{abstract}

Keywords: Energy release rate, Crack, Drag-out, Interfacial shear stress

\section{Introduction}

The efficiency of fiber-reinforced composites is often controlled by the properties of the fiber-matrix interface. Good interfacial bonding (or perfect adhesion), to ensure load transfer from matrix to reinforced fiber, is a primary requirement for effective use of reinforcement properties. Thus, a fundamental understanding of interfacial properties and a quantitative characterization of interfacial adhesion strength can help in evaluating the mechanical behavior and capabilities of composite materials [1,2]. A large number of analytical techniques have been developed for understanding interfacial adhesion of Kevlar and carbon fibers reinforced epoxy matrix such as drag-out adhesion test of U-shaped single fiber specimen, the interfacial shear strength which is an interfacial parameter calculated using Kelly-Tyson as analytical model [3] and the drag-out micromechanical test of U-shaped specimen [4] to measure the maximum pull-out force or peak force from force-displacement curve and also the energy release rate include the thermal stress and fraction force by Nairn[2].

\section{Theory}

The elemental forces balance in fiber reinforce matrix shown in Fig (1).

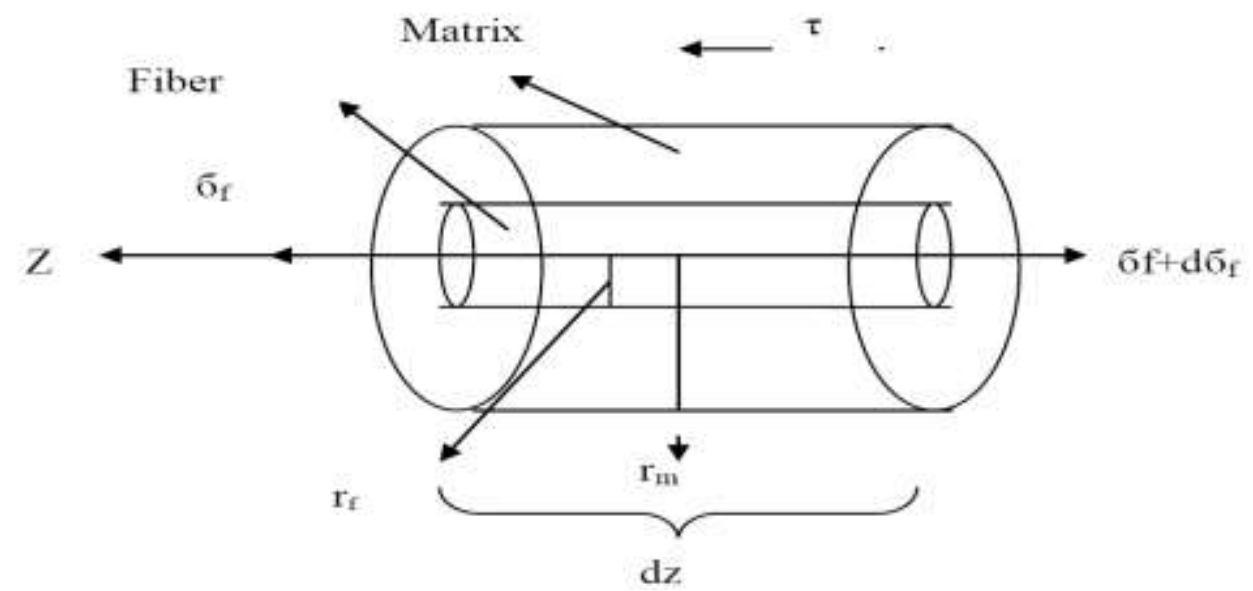

Where :

Fig 1: Directions of shear stresses

$\sigma_{\mathrm{f}}=$ stress applied to the fiber

$\mathrm{r}_{\mathrm{f}}=$ fiber radius

$\mathrm{r}_{\mathrm{m}}=$ matrix radius

$\tau=$ shear stress

$\mathrm{dz}=$ element length and le is the fiber embedded length which equal to

the specimen length 


$$
\begin{aligned}
& \sigma_{f}\left(\pi r_{f}{ }^{2}\right)+\tau\left(2 \pi r_{f} d z\right)-\pi r_{f}{ }^{2}\left(\sigma_{f}+d \sigma_{f}\right)=0 \\
& \frac{d \sigma_{f}}{d z}=\frac{2}{r_{f}} \tau \\
& \int_{\sigma_{o}}^{\sigma_{f}} d \sigma_{f}=\int_{0}^{1} \frac{2}{r_{f}} \tau d z
\end{aligned}
$$

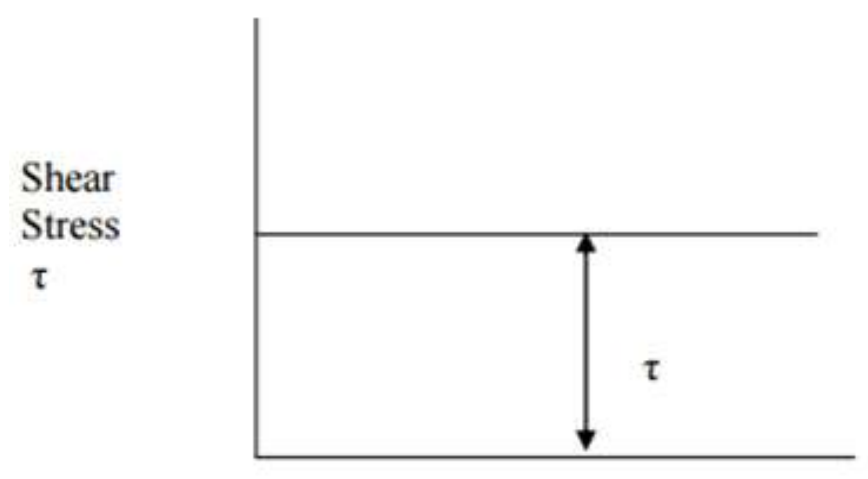

Shear strain $\gamma$

Fig (2) Average shear stress

If we neglected the stress transferred at the end of fiber $\left(\sigma_{0}=0\right.$ at $\left.\mathrm{z}=0\right)$

$\sigma_{f}=\frac{2}{r_{f}} \int_{0}^{1} \tau d z$

To solve the integral we must know $\tau$ as function of Z, Kelly-Tyson model [3] assumed the matrix to be rigidplastic Fig (2) so equation (1) be

$$
\begin{aligned}
& \sigma_{f}=\frac{2 \tau}{r_{f}} \int_{0}^{1} d z \\
& \sigma_{f}=\frac{2 \tau l_{e}}{r_{f}} \\
& \tau=\frac{r_{f} \sigma_{f}}{2 l_{e}} \\
& \sigma_{f}=\frac{F_{p}}{\pi r_{f}{ }^{2}}
\end{aligned}
$$

Substitute equation (3) in equation (2) Kelly-Tyson model [4]

$$
\tau_{i f s s}=\frac{F_{p}}{2 \pi r_{f} l_{e}}
$$

The energy release rate by Nairn include thermal stress and friction force given [8]:

$G_{\infty}(a)=\frac{r_{f}}{2}\left[C_{33 s}\left(\sigma_{d}-k a\right)^{2}+D_{3 s}\left(2 \sigma_{d}-k\left(2 a+\frac{1}{\beta}\right) \Delta T+\left(\frac{D_{3}^{2}}{C_{33}}+\frac{V_{m}\left(\alpha_{T}-\alpha_{m}\right)^{2}}{V_{f} A_{0}}\right) \Delta T^{2}\right]\right.$

Where:

$\beta$ is the shear-lag parameter and defined as: $[6,7]$. 
$\beta^{2}=\frac{2}{r_{1}^{2} E_{A} E_{m}}\left[\frac{E_{A} v_{f}+E_{m} v_{m}}{\frac{V_{m}}{4 G_{A}}+\frac{1}{2 G_{m}}\left(\frac{1}{V_{m}} \ln \frac{1}{V_{f}}-1-\frac{V_{f}}{2}\right)}\right]$

$\sigma_{d}=$ The axial stress at peak force in force- displacement curve

$\mathrm{K}=$ the fractional stress transfer $=\frac{2 \tau_{f}}{r_{f}}$ and $\tau_{f}=\frac{F_{r}}{2 \pi r_{f} l_{e}}$

$\Delta T=$ the different between stress free temperature and the specimen temperature

The volume fraction of fiber $V_{f}$ and matrix $V_{m}$ defined in the reference $[5,8]$

And other constant defined in reference [8]

Fiber and matrix properties listed in table (1) and table (2)

Table 1: The properties of fibers:

\begin{tabular}{|c|c|c|}
\hline Properties & Carbon fiber AS4 & Kevlar fiber \\
\hline Tensile Modulus $\left(E_{A}\right)(\mathrm{Gpa})$ & 380 & 130 \\
\hline $\begin{array}{ll}\text { Transverse modulus } & \left(E_{T}\right)(\mathrm{Gpa}) \\
\end{array}$ & 40 & 10 \\
\hline Axial shear modulus $\quad\left(G_{A}\right)(\mathrm{Gpa})$ & 20 & 15 \\
\hline Axial poisson ratio $\left(v_{A}\right)$ & 0.22 & 0.2 \\
\hline Transverse poisson ratio $\left(v_{T}\right)$ & 0.25 & 0.35 \\
\hline Axial coefficient of thermal expansion $\left(\alpha_{A}\right)_{10^{-6} \mathrm{c}^{-1}}$ & -0.7 & -2 \\
\hline Transverse coefficient of thermal expansion $\left(\alpha_{T}\right) \quad 10^{-6} \mathrm{c}^{-1}$ & 10 & -60 \\
\hline
\end{tabular}

Table 2: The properties of matrix

\begin{tabular}{|l|l|}
\hline Properties & Epoxy \\
\hline Tensile modulus $\left(\mathrm{E}_{\mathrm{m}}\right)(\mathrm{Gpa})$ & 5 \\
\hline Axial shear modulus $\left(\mathrm{G}_{\mathrm{m}}\right)(\mathrm{Gpa})$ & 1.23 \\
\hline Axial poisons ratio $\left(\boldsymbol{U}_{m}\right)$ & 0.35 \\
\hline Axial coefficient of thermal expansion $\left(\alpha_{m}\right) 10^{-6} \mathrm{c}^{-1}$ & 50 \\
\hline
\end{tabular}

\section{Specimen preparation}

A polysiloxane mold of different embedded lengths fiber $(3.09 \mathrm{~mm}, 4.12 \mathrm{~mm}, 5.14 \mathrm{~mm})$ used to get $\mathrm{U}$ shape specimen as shown in Fig. 3 .Three kinds of fiber A kevlar- 49 , carbon fiber with diameters $(0.22 \mathrm{~mm}$, $0.34 \mathrm{~mm}, 0.43 \mathrm{~mm}$ ) and ultra high polyethylene fiber (UHPE) with diameters $(0.45 \mathrm{~mm})$ used to reinforced epoxy matrix cured at room temperature for six days in polysiloxane mold before tensile test by (Microcomputer Controlled electronic Universal Testing machine model WDW-5E).

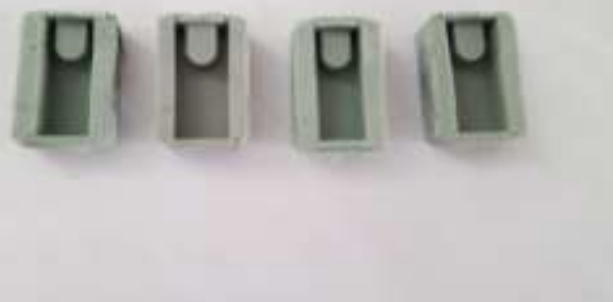

Fig (3) A: Polysiloxane U-shaped mold

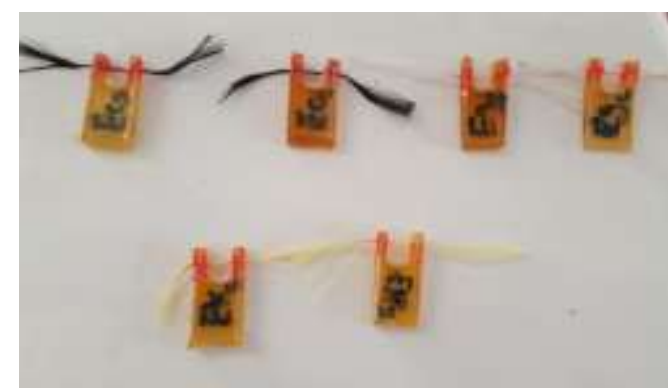

Fig (3) B: U-shaped drag-out specimen 


\section{Results and discussion}

The force vs. displacement curves from drag-out test of specimens shown in Fig (4),(5),(6),(7),(8),(9)

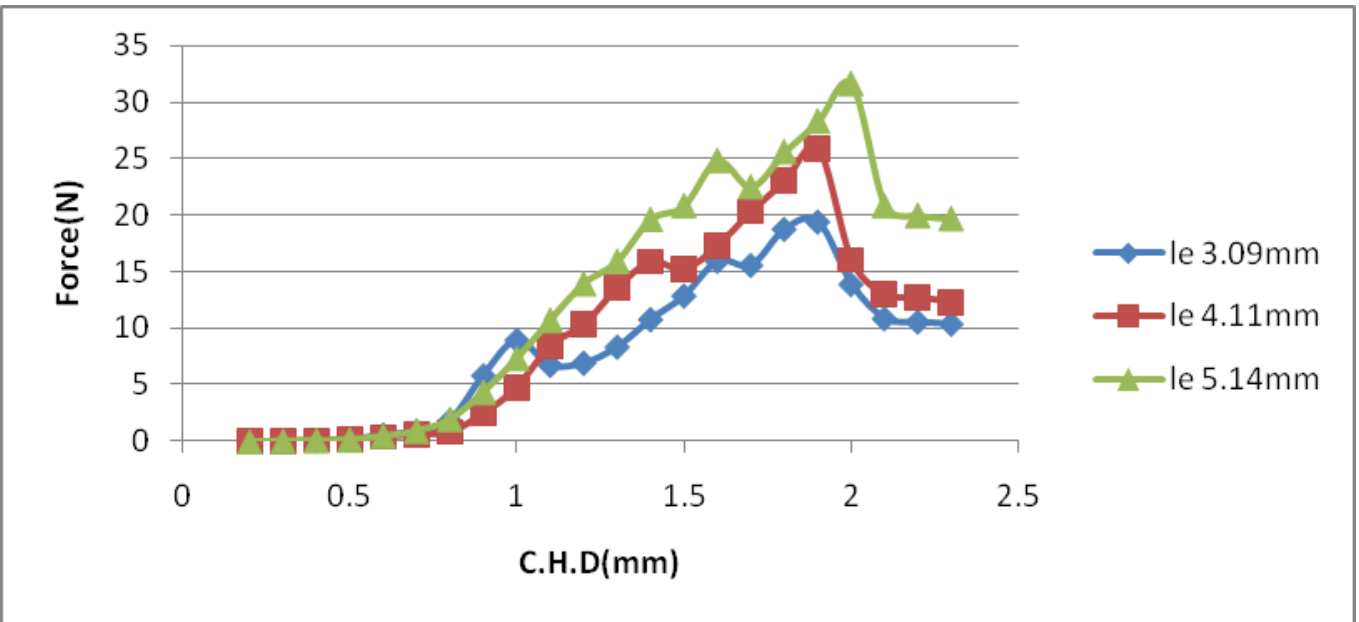

Fig (4) the drag-out force vs. cross head displacement curves for epoxy-carbon fiber post cure at $25^{\circ} \mathrm{C}$ of diameter $(0.22 \mathrm{~mm})$

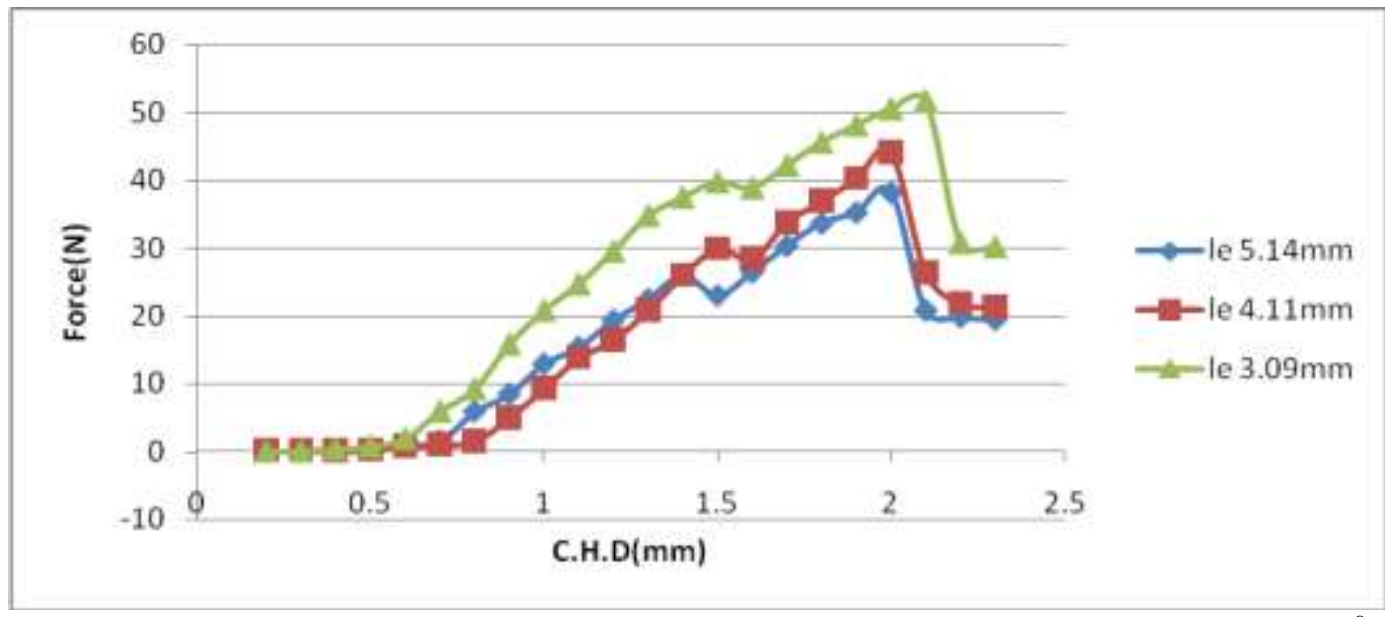

Fig (5) the drag-out force vs. cross head displacement curves for epoxy-carbon fiber post cure at $25^{\circ} \mathrm{C}$ of diameter $(0.34 \mathrm{~mm})$.

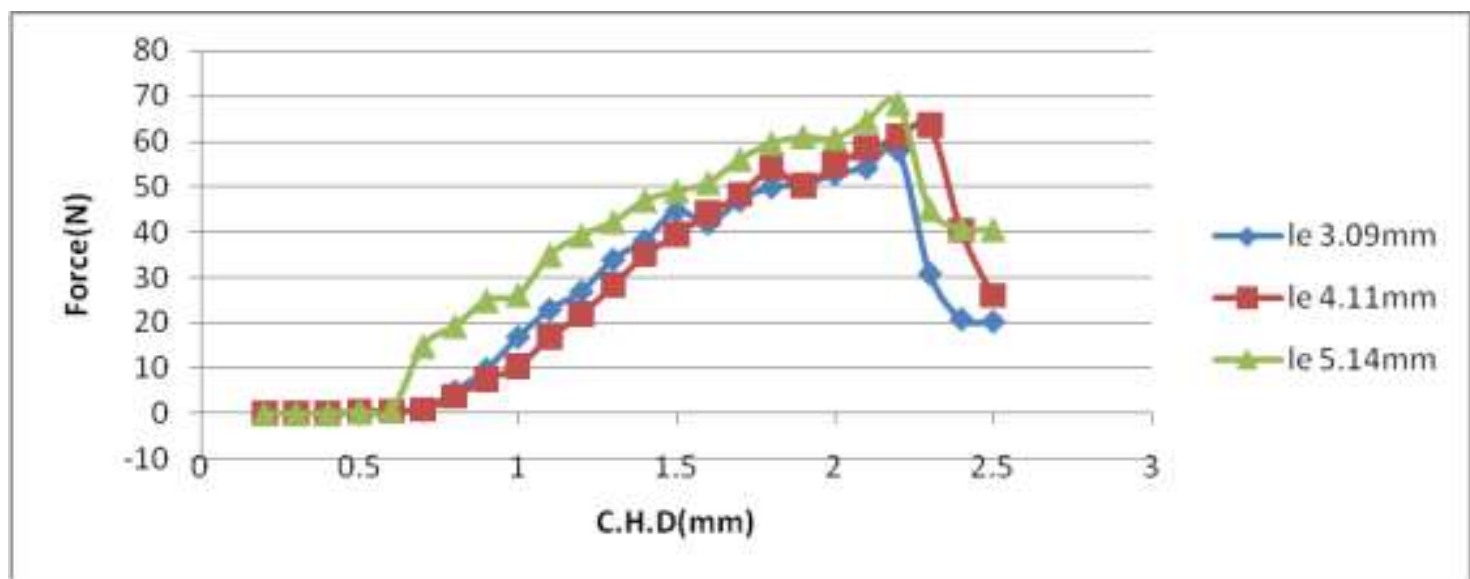

Fig (6) the drag-out force vs. cross head displacement curves for epoxy-carbon fiber post cure at $25^{\circ} \mathrm{C}$ of diameter $(0.43 \mathrm{~mm})$. 


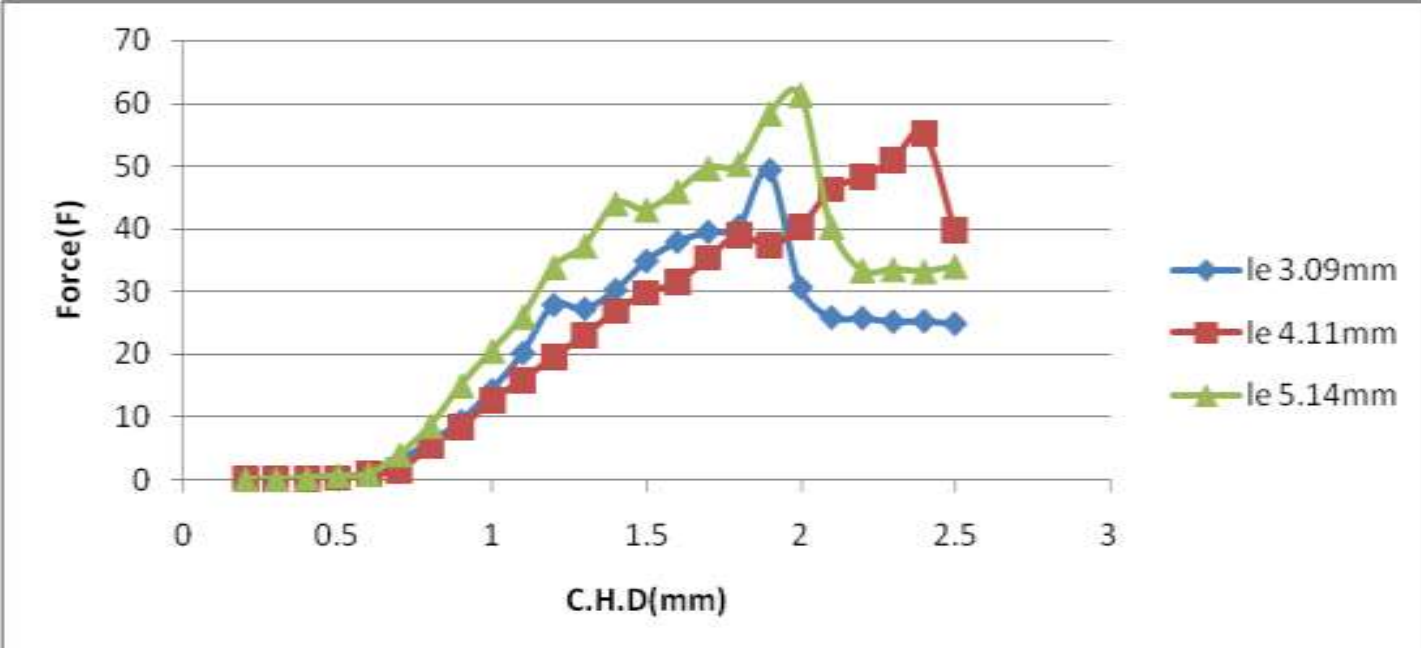

Fig (7) the drag-out force vs. cross head displacement curves for epoxy-Kevlar fiber post cure at $25^{\circ} \mathrm{C}$ of diameter $(0.22 \mathrm{~mm})$.

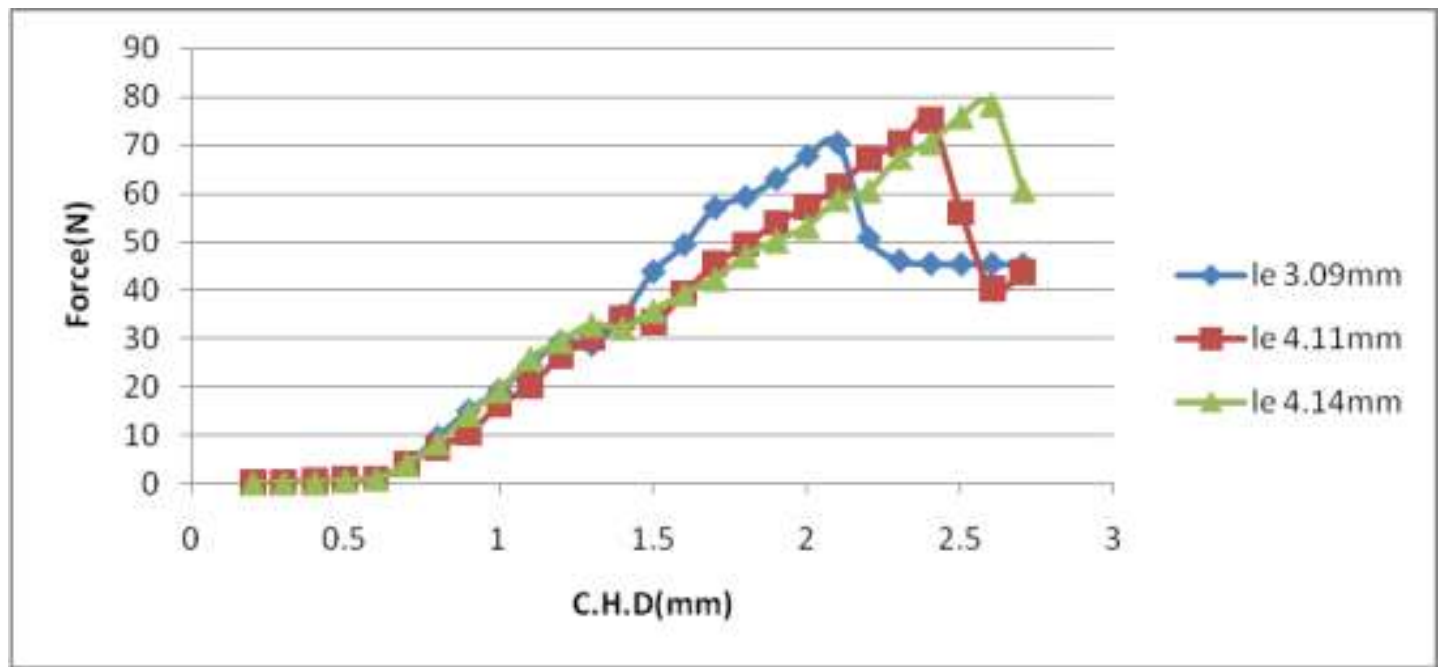

Fig (8) the drag-out force vs. cross head displacement curves for epoxy-Kevlar fiber post cure at $25^{\circ} \mathrm{C}$ of diameter $(0.34 \mathrm{~mm})$.

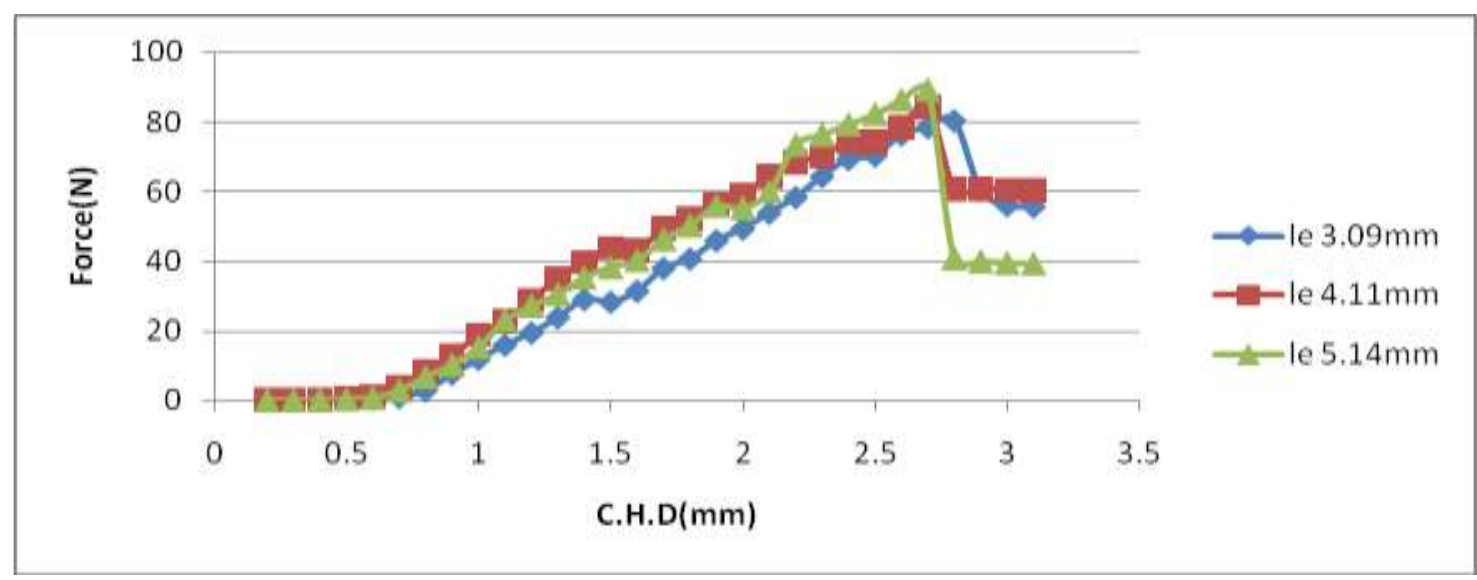

Fig (9) the drag-out force vs. cross head displacement curves for epoxy-Kevlar fiber post cure at $25^{\circ} \mathrm{C}$ of diameter $(0.43 \mathrm{~mm})$. 


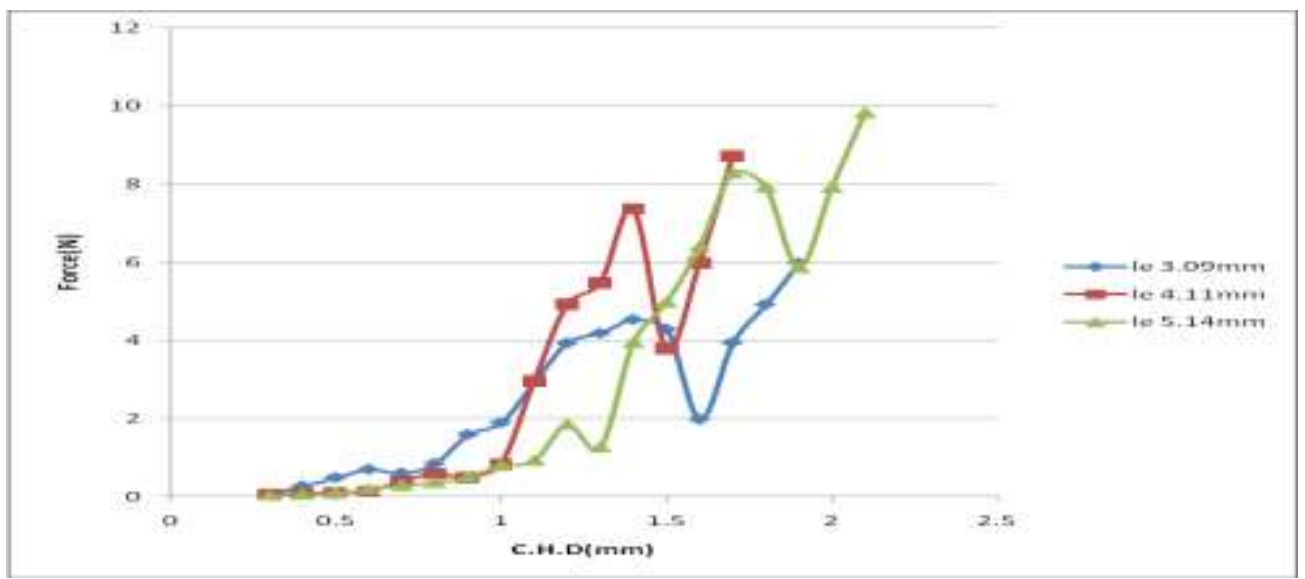

Fig (10) the drag-out force vs. cross head displacement curves for epoxy- polyethylene fiber post cure at $25^{\circ} \mathrm{C}$ of diameter $(0.45 \mathrm{~mm})$.

The energy release rate G(a) for an interfacial debond crack by Nairn model, the energy release rate is an indication for crack propagation at interface. Fig(4) shown the peak force (full debound) for different for embedded fiber lengths and as the fiber length increase the peak force and then the energy release rate increased as surface area between fiber and matrix be larger and then the bound strength increase.

The energy release rate increase when fiber diameter and embedded length increase as in Fig (11) (12)

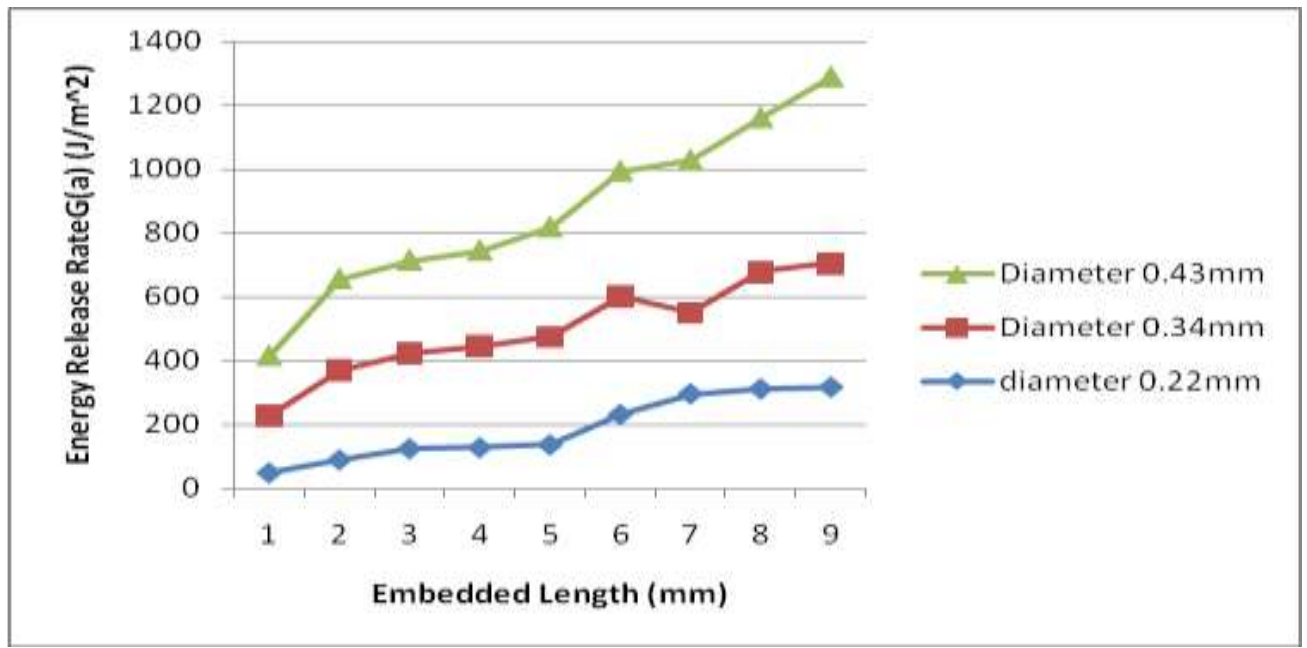

Fig (11) Energy release rate for Kevlar fiber at three diameters

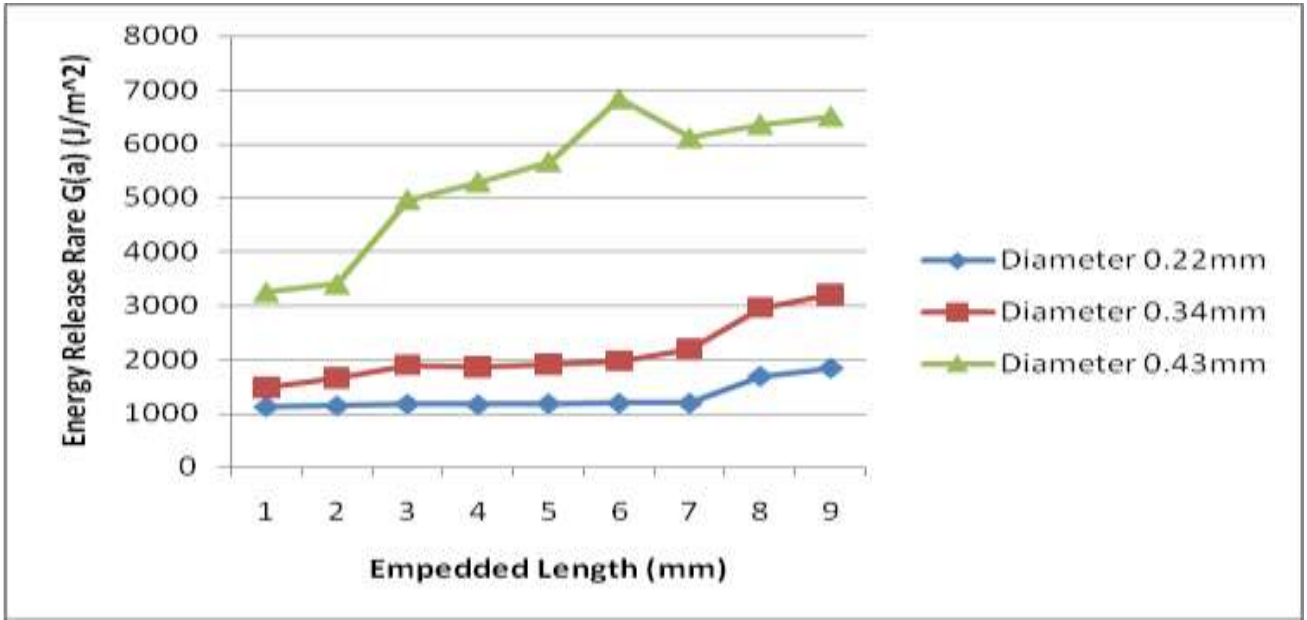

Fig (12) Energy release rate for carbon fiber at three diameters 
The energy release rate is increase when the surface area of the fiber increase that is to mean the adhesion area between fiber and matrix increase (perfect adhesion) but there are some abnormal behavior in samples which shown a decrease in the in energy release rate when increasing the diameter that can be explained this adhesion between the fiber and the matrix is imperfect adhesion for several reasons due to the presence of bubbles between fiber and matrix or a fiber containing filaments.

The energy release rate for polyethylene fiber are very low in compared with the carbon fiber and Kevlar fiber as in Fig (10) because of the poor adhesion of ultra high polyethylene (UHPE) fiber with epoxy resin due to its surface structure characteristics it have low friction coefficient, highly resistant to corrosive chemicals, the surface roughness polyethylene fiber, low surface energy.

\section{Conclusion}

1. Nairn model include interfacial shear strength, thermal stress and friction.

2. The increasing in the embedded length of the fiber and diameter, which leads to increased adhesion area does not mean increasing of the energy released rate, for several reasons due to the presence of bubbles between fiber and matrix or a fiber containing filaments (not perfect adhesion)

3. Using nano fiber reinforce polymer matrix the adhesion between fiber and matrix will be perfect.

4. Drag-out test is more flexible than pull-out and microbond tests.

5. The high difference between the values of frictionless energy release rate and the values of energy release rate indicated the importance of friction effect. at the friction part of all dag-out force-displacement curves there are two kinds, slip-hardening, if the surface of matrix is more hard than fiber surface caused surface fiber abrasion and the friction force would increase over peak force, the second kind was slip-soften occurred when the surface of fiber is more hard than matrix surface and the friction force would be less than the peak force.

\section{Reference}

[1]. H. I . Jaffer, H. M. Hasan, "The Energy Release Rate at Knik and Peak Points for Polyester-kevlar fiber and polyester-Polyethylene fiber", quarterly.vol 12,Issue:3,PP.1-14,2007

[2]. Nairn J.A., Liu C.H. , Mendels D.A. and Zhandarov S , " Fracture Mechanics Analysis of the Single-Fiber Pull-Out Test and the Microbond Test Including The Effects of Friction and Thermal Stresses", J.of composites, September,pp 9-12 (2001).

[3]. A.Kelly and W.R.Tyson," Tensile Properties of Fiber-Reinforced Metal Copper/Tungsten and Copper/ Molybdenum “,J.Mech.Phys.Solids vol,13,329,(1965)

[4]. Nuriel S., Katzb A., and Wagnera H.D., " Measuring fiber-matrix interfacial adhesion by means of a 'drag-out' micromechanical test ",Composites: Part A ,36, PP.33-37,(2005).

[5]. John A.Narin ," Analytical fracture mechanics analysis of the pull-out test including the effects of friction and thermal stresses", Advance composites Letters, Vol 9, pp.373-383, (2000),

[6]. Nairn J.A., Mendels D.A., " On the use of planar shear-lag methods for stress-transfer analysis of multilayered composites ", Mechanics of Materials 33 ,PP. 335-362,(2001).

[7]. Nairn J.A., Wagner H.D., " A Revised Shear-Lag Analysis of an Energy Model for Fiber-Matrix Debonding ",J. Advanced Composite Letters,Vol 5, No. 5,PP. 131-135,(1996).

[8]. Scheer R.J., Nairn J.A., " A Comparison of Several Fracture Mechanics Methods for Measuring Interfacial Toughness with Mic robond Tests ", J. Adhesion, Vol. 53 pp. 45-68, (1995). 